\title{
PRACTICE MANAGEMENT
}

\section{Text your patients}

The majority of the British public now have a mobile phone and now a new service is set to connect you with your patients in the most convenient way.

Developed by 4 productions, dentists can now send a set or ad hoc messages to their patients. They can use them to make appointments or send reminders at a predetermined time decided between you and your patient.

Messages can be sent to a single recipient, to a group of individuals or to an identified patient sector. The SMS system allows you to transfer messages once, repeatedly, seasonally or sequentially. For more information phone 01296616600. Reader response number 56

\section{MEDiVision's PiC cd}

Marketing dentistry and raising public awareness of developments in possible treatments is important for a successful and profitable practice. To help dentists MEDiVision offers a flexible, affordable patient education and practice marketing program, PiC (Practice Information Centre).

Included on the PiC CD is a marketing tool, which runs in an endless loop, entertaining and informing patients while they wait. The program includes 130 illustrated and animated marketing messages, some relating to treatment, customer care and also promoting different products.

MEDiVision claims the system menu allows each individual practice to select those messages most appropriate to its own patients, and messages can be personalised and amended to include specific practice details or to promote the particular services the practice offers

The MEDiVision marketing program features a wide range of options and facilities, and is readily adaptable to promote a broad general campaign. The program is designed to run on older as well as state of the art equipment.

For more information phone 01908 265565.

Reader response number 57

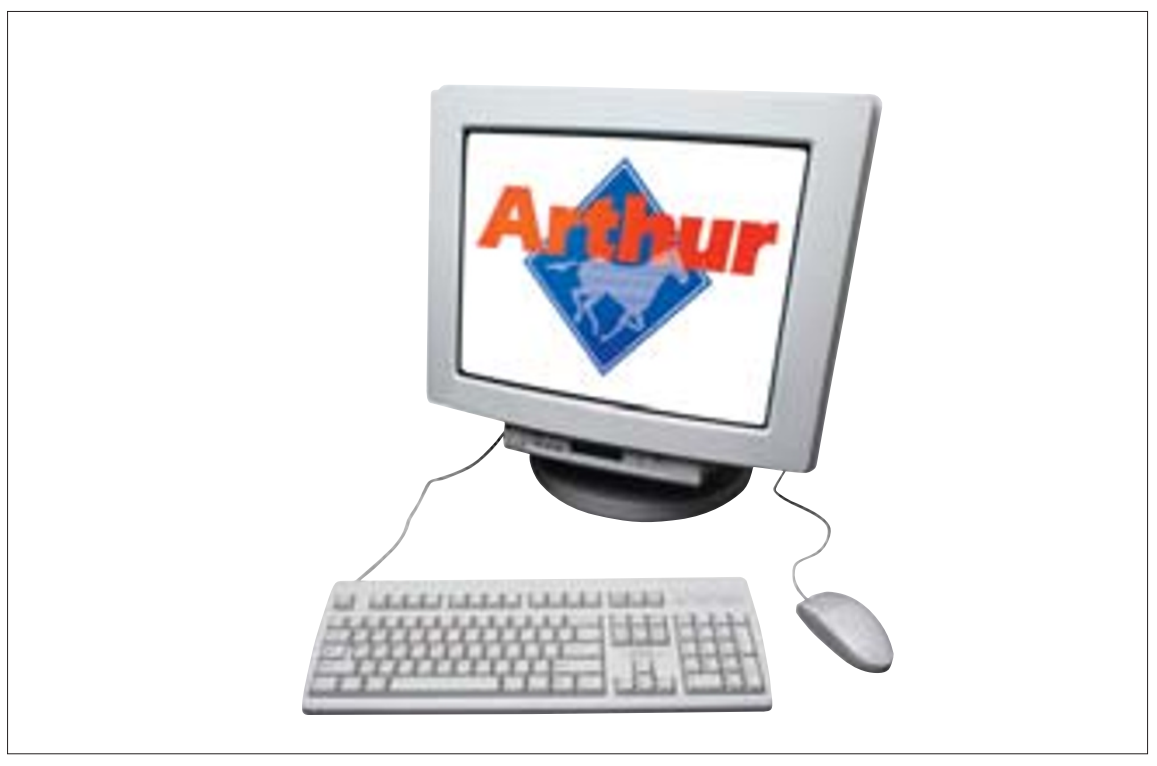

\section{The surgery module from TMS}

'Arthur' for Windows surgery module includes a straightforward, simple to use, clinical charting facility to suit the needs of all dental practitioners. Chart entries can be made either with a mouse click or the TMS QuickPen. TMS claims keeping clinical charts up to date has never been easier. Charting treatments with 'Arthur' makes it easy to record and differentiate between existing, planned and completed treatments

The versatility of 'Arthur's surgery module clinical charting introduces a number of practical benefits and time saving advantages to a busy treatment schedule. Charting is clear and easy to read from the chair side. The graphics for the existing mouth state are clear and unambiguous, indicating drifts in teeth, root present, root filled teeth, pin inserted, caries present, and mixed dentition tooth. There is easy access to tooth history on a single tooth by using a filter to search for specific criteria.

For further information phone or to arrange a demonstration call 0129661660. Reader response number 55

\section{Show your loyal patients some reward}

Practice Plan focuses on a private maintenance plan, which enables member practices to achieve a committed core of loyal patients. The plan benefits patients who attend regularly for routine examinations and hygienist visits. The maintenance scheme also provides patients with the freedom to take up any treatments recommended or requested. A maintenance-based plan helps to eliminate financial risk.

It is claimed Practice plan claims that practices using the Practice Plan Scheme have found it is well received and works well for both the practice and its patients. With a strong emphasis on quality, Practice Plan will also design your very own brochure to present your new practice image.

For more information phone 01691677 966. R R R R $\quad$ Reader response number 58

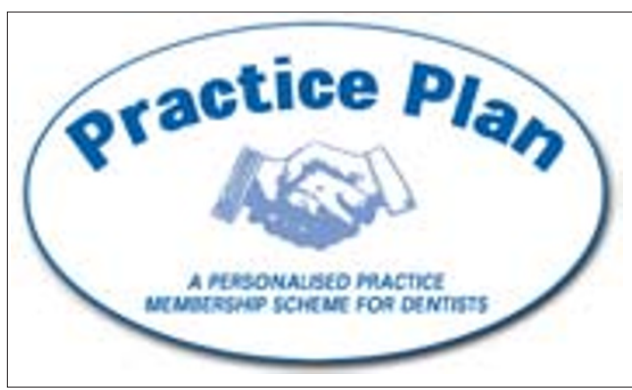




\section{Private Practice Software from Rushcliff}

Private Practice Software (PPS) from Rushcliff is a total practice management package. Rushcliff claims PPS allows dentists to effectively manage their practice records including: Client Details, Medical History, Appointments Diary, Clinical Notes, Client Journal, Invoicing, Reminders/Letters and Reports. PPS is also offering a variety of optional additional modules including: Charts and Diagrams, Document Management and Practice Expenditure.

Rushcliff claims PPS is ideal for the clinic, health centre or individual practitioner and includes all dentists needs to help them run their practices. Dentists can operate PPS on either a single PC or on a practice network.

For more information phone 015824610160 or visit www.rushcliff.com/pps.

Reader response number 59

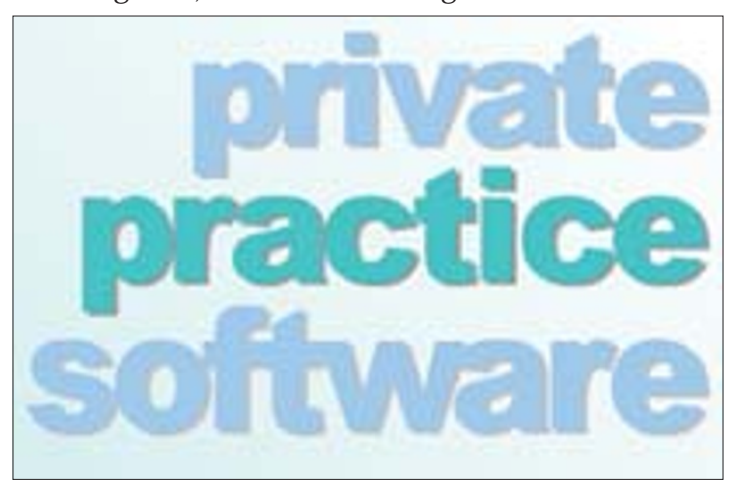

\section{Software of Excellence get the rights}

Software of Excellence International (SOEI) has acquired the world-wide rights to a new 3D animated patient education module which will replace its existing EXPLAIN module.

In the first instance, EXPLAIN 3D will be

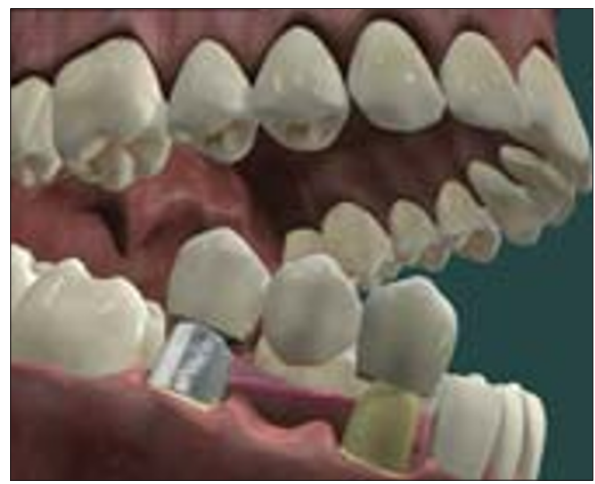

integrated into EXACT7 as a tab for easy access and later a new interface will be developed. Users will be able to attach specific video sequences to services which will then appear on treatment plans with a little icon. The icon not only reminds the clinician of the availability of the relevant animated explanation, but can also be easily initiated by clicking on the icon to play the sequence.

SOEI has contracted with 3DTooth to create additional sequences over the next several years to enhance both patient education tools and the 3D models and animation in its core products.

For more information phone 01580890 046 or visit www.soeidental.com or email info@soeuk.com.

Reader response number 60

\section{Get a better understanding of your market}

Clarity claims to offer dentists cost effective dental marketing to all dental practices. The service aims to clear the fog of confusion that often surrounds practice promotion with clear thinking and clarity of purpose. Clarity brings business marketing knowledge to individual practices.

Clarity aims to exploit a wider range of marketing options than the usual advertisements in local newspapers or yellow pages, attacking the market through different, new and exciting mediums to attract new patients who will stay loyal.

They also claim that they will get to the heart of your brand, direct your message and reach your target market, thus enabling your surgery to build the kind of practice you desire. For more information phone 016422535371.

Reader response number 61

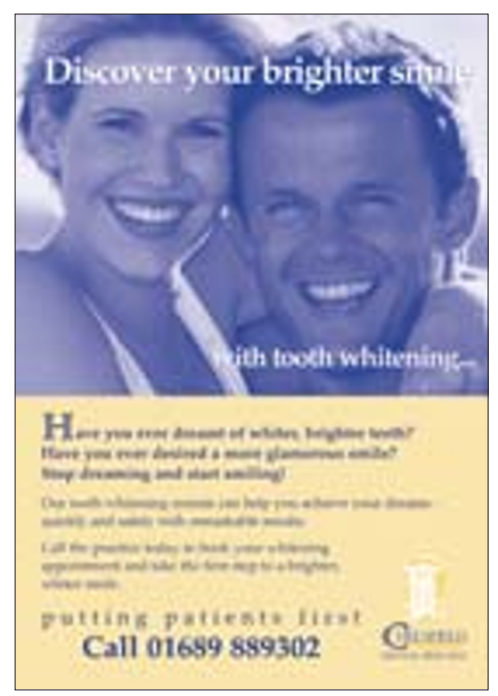

